\title{
A Study to Analyse the Effectiveness of Physical Therapy and Wedged Foot Orthotic Devices on Pain in Runners with Pronated Foot
}

\section{U Albert Anand ${ }^{1 *}$, Bernard Dino Santiago ${ }^{2}$, Percival Victor Beuke ${ }^{3}$, Lizette Fernandez ${ }^{2}$, Sherwin Abat $^{2}$, Mohamed Sameer Gamieldien ${ }^{4}$ and Tasneem Cariem $^{3}$}

${ }^{1}$ Mediclinic Al Ain Hospital, UAE

${ }^{2}$ Physiotherapy, Philippines

${ }^{3}$ Physiotherapy, South Africa

${ }^{4}$ Orthotist, South Africa

*Corresponding Author: U Albert Anand, Mediclinic Al Ain Hospital, UAE

Received: September 26, 2019; Published: October 23, 2019

DOI: 10.31080/ASOR.2019.02.0117

\begin{abstract}
Background: Running is one of the most popular forms of aerobic exercises and widely perceived to be beneficial to the cardiovascular and musculoskeletal endurance. In recent years, experts noted an increasing rate of injuries (24 - 65\%) occurring in long distance runners and suggested that these injuries are related to the tremendous demands put on their lower extremities during running. Objective: The purpose of the study was to find out the effect of Physical therapy and wedged foot orthotics on reducing the intensity of pain and onset of pain time in runners with pronated foot.

Design: Pre test-post test Experimental Study design

Setting: The study was conducted in Out Patient Department of physiotherapy, Tertiary Hospital Al ain, UAE.

Patients: 20 subjects between 18 - 35 years old with on pain in runners with pronated foot were randomly assigned into 2 groups. Interventions: Group A (Experimental) received a flat insole with 5 rear foot posting and physical therapy session. In Group B (Control) group received a non-wedged flat insole on the same material and following the same physical therapy session.

Measurements: 60 minute treadmill test outcome measured were onset of pain time and pain intensity were measured with Visual analogue scale.

Conclusion: Thus the study concluded that physical therapy and wedged foot orthotic devices helps in reducing pain intensity and delays the pain onset of runners with pronated foot.

Keywords: Pronated Foot; Wedged Orthotics; Runners; Physical Therapy
\end{abstract}

\section{Introduction}

Running is one of the most popular forms of aerobic exercises and widely perceived to be beneficial to the cardiovascular and musculoskeletal endurance. In recent years, experts noted an increasing rate of injuries (24 - 65\%) occurring in long distance run- ners and suggested that these injuries are related to the tremendous demands put on their lower extremities during running.

The ankle and foot complex are the most distal joints of the skeletal system from the weight bearing perspective. The function is to 
appropriately distribute the weight bearing stresses during function. Their normalcy in anatomy and mechanics is hence essential to minimize abnormal loading and predisposition to a dysfunction [1]. The most common cause of heel pain is plantar fasciitis; it is usually caused by biomechanical imbalance resulting in tension along the plantar fascia [2].

It is believed that running injuries result from a combination of extrinsic factors (training error, shoe wear, running surface and training pattern) and intrinsic factors (poor flexibility, malalignment, variations in anthropometry, previous injury and running experience).

Researchers studying contributing factors for running injuries have suggested that pronated foot, defined as the foot with excessive compensatory pronation of subtalar joint and midtarsal joint during weight-bearing activities, might impair the stability of the foot and thus have an impact on the occurrence of patella femoral pain or foot pain.

Managements of the pronated foot generally focus on maintaining the integrity of the supporting tissue, ensuring full range of foot motion, and supporting the foot in an optimal alignment. Among various intervention methods, foot orthosis was designed to correct or accommodate the biomechanical defects of the lower extremity.

Physical therapy interventions and Application of foot orthosis has been shown to successfully reduce symptoms in patients with pronated foot, and to alter the lower extremity biomechanics such as reduction of movement range and change of timing of calcaneal eversion and tibial rotation in both healthy adults and patients with painful knee or foot.

Studies by Eng and Pierrynowski, and by Mundermann., et al. suggest that the soft foot insole with a medial post could effectively improve lower extremity kinematics and kinetics such as reduced ankle/foot rotations in the frontal and transverse plane, and decreased maximum foot eversion and ankle inversion moment. In this study we believe that a soft foot insole with shock absorbing material and wedge support would offer a less expensive and lightweight orthotic choice for runners who experienced painful symptoms during running.
The Aim of study is to find out the effectiveness of Physical therapy and wedged foot orthotic devices used to reduce the pain and delay the onset of pain in runners with pronated foot.

\section{Methods}

The study was pre-test and post-test experimental study design. All the subjects underwent a clear examination to diagnose the navicular height and pronated foot were selected and divided into two groups. The subjects were instructed clearly on the study, the potential benefits and harms of the study was adequately explained to the subjects, they were given 24 hours to confirm their participation, their willingness to participate was obtained and the subjects had permitted to withdraw from study at any point of time. Informed consent was obtained from all the participants and the study was approved by the tertiary hospital ethical committee.

The study included the subjects with Moderate Pain over the patello femoral joint and plantar aspect of heel not more than 5 in Visual analog scale, age group from 18 yrs to 35 yrs, Both sex were included andClinically diagnosed runners with pronated foot. whereas subjects with Ankle and foot stiffness, Tarsal tunnel syndrome, Calcaneal stress fracture, Plantar fascia rupture, Histories of knee ligament or meniscal injuries, Patellar dislocation, or subluxation, Knee surgeries within three months or evidence of knee joint effusion, Ankle sprain within the previous three months, current orthosis treatment, Leg length discrepancies $>2 \mathrm{~cm}$, Pathological or neurological disorders were excluded from the study.The pronated foot was defined by:

- $\quad$ Navicular height difference between weight bearing and non-weight-bearing stance $>10 \mathrm{~mm}$.

- Non-weight-bearing rear foot Varus $>5$ or weightbearing calcaneal valgus $>5$.

The subject selection was based on the inclusion and exclusion criteria. The subjects were explained with VAS for pain and 60 minute Treadmill running test. 20 subjects were randomly selected and assigned into two groups. 10 subjects were in each group. In Group A (Experimental) received a flat insole with 5 rear foot posting. The insole was made of 2 -mm Poron, a rubberlike material with good impact absorbing capability, and the rear foot posting was made from an off-the-shelf 5 wedge of ethyl vinyl acetate (EVA). The medial wedge extended from the lon- 
gitudinal midline to the medial edge of the insole and was 6 to 8 $\mathrm{cm}$ in length depending on subject's foot size Subjects underwent a physical therapy session for 4 days per week. One session stands for duration of 30 minutes.

The session included warm up exercises (These exercises included quadriceps, gastrocnemius and soleus, hamstrings, iliotibial band and hip flexor stretches) for 3 minutes, foot exercises were given for 10 minutes in addition is in to this stretching is incorporated for 10 minutes. Ultrasound was given as an adjunct to the treatment session for duration of 7 minutes $1.3 \mathrm{MHZ}$ using sonopulse. In Group B (Control) group received a non-wedged flat insole on the same material and following the same physical therapy session. We used a treadmill for both groups to perform the 60-minute running test as the outcome testing task. Prior to the treatment, the pre-test value for pain was noted using visual analogue scale and the score for onset of pain was recorded as the duration of the running test (test ended at the onset of pain). Following treatment the patient was advised to continue the home programme and thanked for their co-operation. The data was noted separately and was taken for analysis. The outcome measures were Pain and Onset of pain time, which were assessed by Visual analogue scale and 60 minute treadmill test.

Analysis of Data and Results

Statistical analyses were performed using the Statistical Package for the Social Science(SPSS). The Paired " $\mathrm{t}$ " test is used to compare the pre andpost test values of intensity of pain and onset of pain in during 60 minute treadmill test. The unpaired " $\mathrm{t}$ " test is used to compare the post test values of group A and B.

The student' $t$ ' test was done to analyze the pre and post test means of group A and B. Paired ' $t$ ' test showed that both group $A$ and $B$ significantly reduce the pain intensity. For pain intensity, Group A calculated ' $t$ ' value is $15.0>$ table ' $t$ ' value 2.262, Group B calculated' $t$ ' value is $11.2>$ table ' $t$ ' value 2.262. In Unpaired' $t$ ' test, the pre test mean analysis showed that there is no difference between the groups. Analysis of post test means showed that there is significant difference between the groups for pain intensity. (calculated' $t$ ' value is $5.23>$ table ' $t$ ' value 2.101).

The student ' $t$ ' test was done to analyze the pre and post test means of group A and B. Paired ' $t$ ' test showed that both group $A$ and $B$ significantly reduce the pain intensity. For pain intensity,
Group A calculated' $t$ ' value is $60.7>$ table' $t$ ' value 2.262, Group B calculated ' $t$ ' value is $36.6>$ table ' $t$ ' value 2.262. In Unpaired' $t$ ' test, the pre test mean analysis showed that there is no difference between the groups. Analysis of post test means showed that there is significant difference between the groups for pain intensity. (calculated' $t$ ' value is $1.07>$ table' $t$ ' value 2.101).

\begin{tabular}{|c|c|c|c|c|c|}
\hline $\begin{array}{l}\text { Statistical } \\
\text { test }\end{array}$ & $\begin{array}{c}\text { Groups } \\
\text { / test } \\
\text { scores }\end{array}$ & Mean & $\begin{array}{l}\text { Standard } \\
\text { deviation }\end{array}$ & $\begin{array}{c}\text { 't' } \\
\text { value }\end{array}$ & $\begin{array}{c}\text { Table } \\
\text { 't' } \\
\text { value }\end{array}$ \\
\hline \multirow{2}{*}{$\begin{array}{l}\text { Paired ' } t \text { ' test } \\
\text { - Group A }\end{array}$} & Pretest & 28.9 & 1.29 & \multirow[t]{2}{*}{60.7} & \multirow[t]{2}{*}{2.262} \\
\hline & Posttest & 56.4 & 0.97 & & \\
\hline \multirow{2}{*}{$\begin{array}{l}\text { Paired 't' test } \\
\text { - Group B }\end{array}$} & Pretest & 28.3 & 1.16 & \multirow[t]{2}{*}{36.6} & \multirow[t]{2}{*}{2.262} \\
\hline & Posttest & 45.6 & 1.07 & & \\
\hline \multirow{2}{*}{$\begin{array}{l}\text { Unparied ' } \mathrm{t} \text { ' } \\
\text { test - pretest }\end{array}$} & Group A & 28.9 & 1.29 & \multirow[t]{2}{*}{1.10} & \multirow[t]{2}{*}{2.101} \\
\hline & Group B & 28.3 & 1.16 & & \\
\hline \multirow{2}{*}{$\begin{array}{l}\text { Unpaired ' } \mathrm{t} \text { ' } \\
\text { posttest }\end{array}$} & Group A & 56.4 & 0.97 & \multirow[t]{2}{*}{23.8} & \multirow[t]{2}{*}{2.101} \\
\hline & Group B & 45.6 & 1.07 & & \\
\hline
\end{tabular}

Table1: Showing Student 'T' Test: Forpain Onset Time.

\begin{tabular}{|c|c|c|c|c|c|}
\hline $\begin{array}{l}\text { Statistical } \\
\text { test }\end{array}$ & $\begin{array}{c}\text { Groups } \\
\text { / test } \\
\text { scores }\end{array}$ & Mean & $\begin{array}{l}\text { Standard } \\
\text { deviation }\end{array}$ & $\begin{array}{c}\text { 't' } \\
\text { value }\end{array}$ & $\begin{array}{c}\text { Table } \\
\text { 't' } \\
\text { value }\end{array}$ \\
\hline \multirow{2}{*}{$\begin{array}{l}\text { Paired ' } t \text { ' test } \\
\text { - Group A }\end{array}$} & Pretest & 6.80 & 0.789 & \multirow{2}{*}{15.0} & \multirow{2}{*}{2.262} \\
\hline & Posttest & 1.80 & 0.919 & & \\
\hline \multirow{2}{*}{$\begin{array}{l}\text { Paired ' } t \text { ' test } \\
\text { - Group B }\end{array}$} & Pretest & 7.00 & 0.667 & \multirow{2}{*}{11.2} & \multirow{2}{*}{2.262} \\
\hline & Posttest & 3.90 & 0.876 & & \\
\hline \multirow{2}{*}{$\begin{array}{l}\text { Unparied ' } \mathrm{t} \text { ' } \\
\text { test - pretest }\end{array}$} & Group A & 6.80 & 0.789 & \multirow{2}{*}{0.612} & \multirow{2}{*}{2.101} \\
\hline & Group B & 7.00 & 0.667 & & \\
\hline \multirow{2}{*}{$\begin{array}{l}\text { Unpaired 't' } \\
\text { posttest }\end{array}$} & Group A & 1.80 & 0.898 & \multirow{2}{*}{5.23} & \multirow{2}{*}{2.101} \\
\hline & Group B & 3.90 & 0.876 & & \\
\hline
\end{tabular}

Table 2: Showing Student 'T' Test: For Pain Intensity.

\section{Discussion}

The purpose of the study was to find out the effect of Physical therapy and wedged foot orthotics on reducing the intensity of pain and onset of pain time in runners with pronated foot. Many causative factors for heel pain in runners have been hypothesized literatures, yet the etiology is unknown. Both intrinsic and extrinsic factors are responsible for causing problem in the foot. One of the common causes noted is abnormal foot posture in the foot [3]. 
There is a strong relationship found between pronated foot type and chronic heel pain [4]. Chronic heel pain results from excessive pronation. Normally pronation occurs in the foot during stance phase of gait. It helps the feet to adapt the ground and also absorb the shock during walking. Excessive pronation cause inward rotation of leg which creates an abnormal amount of stretching and pulls the ligament and tendon attaching the heel, which results in pain [5].

Wearing the custom-made orthosis resulted in significant changes of lower extremity kinematics and kinetics, such as decreased maximum rear foot eversion angle and velocity and lower internal ankle inversion moment in healthy adults [6]. During gait cycle, excessive foot pronation causes inward roll of foot, results in lowering of arch. Flattened arch makes foot unstable, prolonged instability results in injury or microtrauma to the soft tissue structures around the foot result in pain and dysfunction in heel [7].

Ultrasound increases blood flow and reduce the inflammation and pain [8]. Ultrasound helps in reducing the pain and muscle spasm, It reflexes activity of muscle and spasm [9].

Pronation is a dysfunction can cause due to tightening of gastroscopes. Gastroscopes tightening alter the position of calcaneus inturn result in overstretching of fascia result in pain. Stretching exercises helps in reduction of fascial tightening and reduce the abnormality of foot [10]. Both sustained and intermittent stretching exercises helpful in the management of painful heel syndrome [11]. Stretching exercises help in reducing symptoms of chronic plantar heel pain [12]. Correction of pronated foot helps to relieve pain and discomfort. Long-term releif of pain is done by complete remedy of the aggravating pronation factors [4].

Treatment should focus in prevention of excessive pronation and there by controlling valgus of calcaneum, which intern reduces tension in the passive structures around the foot [13].

\section{Conclusion}

Thus the study concluded that physical therapy and wedged foot orthotic devices helps in reducing pain intensity and delays the pain onset of runners with pronated foot.

\section{Acknowledgements}

Authors are thankful to all the Team members of the Tertiary Hospital, Al Ain, UAE.

\section{Conflicts of Interest}

None.

\section{Bibliography}

1. Deepak Sebastian. A manual therapy approach to musculoskeletal Dysfunction, Principles of manual therapy first edition ISBN -81-8061-504-9. (2005).

2. Barrett SJ and O'Malley R. "Plantar fasciitis and other causes of heel pain”. American Family Physician 59.8 (1999): 2200-2206.

3. Rome K., et al. "Effectiveness of foot orthoses for treatment and prevention of lower limb injuries". Sports Medicine 38 (2008): 759-779.

4. Kwong PK., et al. "Plantar fasciitis: mechanics and pathomechanics of treatment”. Clinics in Sports Medicine 7 (1988): 119126.

5. Donatelli RA. "Abnormal biomechanics". In: Donatelli RA, editor. Biomechanics of the Foot and Ankle. 2nd ed. Philadelphia, PA: FA Davis; (1996): 34-72.

6. Mündermann A., et al. "Foot orthotics affects lower extremity kinematics and kinetics during running". Clinical biomechanics (Bristol, Avon) 18.3 (2003): 254-262.

7. Viel E and Esnault M. "The effect of increased tension in the plantar fascia: a biomechanical analysis". Physiotherapy Theory and Practice 5 (1989): 69-73.

8. Robertson JV and Baker GK. "A review of therapeutic ultrasound: Effectiveness studies". Physiotherapy Theory 81 (2001): 1339-1350.

9. Fountain Fp., et al. "Decrease in muscle spasm produced by ultrasound, hot packs, and infrared radiation". Archives of Physical Medicine and Rehabilitation 41 (1960): 293-298.

10. Cole C., et al. "Platar facitis evidence based review of the diagnosis and therapy". American Family Physician 72 (2005): 2237-2242.

11. Porter D., et al. "The effects of duration and frequency of Achilles tendon stretching on dorsiflexion and outcome in painful heel syndrome: a randomized, blinded, control study". Foot and Ankle International 23.7 (2002): 619-624.

12. Robroy L Martin and Todd E. "Davenport "Stephen F Reischl Heel Pain-Plantar Fasciitis: Revision". Journal of Orthopaedic and Sports Physical Therapy 44.11.

13. Lori A Bolgla and Terry R Malone "Plantar Fasciitis and the Windlass Mechanism: A Biomechanical Link to Clinical Practice". Journal of Athletic Training 39.1 (2004): 77-82.

Volume 2 Issue 11 November 2019 (C) All rights are reserved by $\mathrm{U}$ Albert Anand., et al. 